\title{
PENERAPAN METODE MIND MAPBERBASIS DRILL UNTUK MENINGKATKAN KEMAMPUAN BERBICARA MAHASISWA DI PRODI PBSI IKIP PGRI BOJONEGORO
}

\author{
Nur Alfin Hidayati \\ IKIP PGRI Bojonegoro \\ nikidanajwasalsabila@gmail.com
}

\begin{abstract}
This research was motivated by the low value of speaking practice in PBSI IKIP PGRI Bojonegoro. The purpose of this research is to describe; (1) to increase the activeness of speaking skills using the drill-based mind map method; (2) improvement of learning outcomes for speaking skills using the drill-based mind map method for IA level students in the PBSI IKIP PGRI Bojonegoro. This research uses Classroom Action Research through two cycles, each cycle consisting of planning, implementing, observing, reflecting. Collecting data using observation instruments, documentation, interviews, and speaking practice tests. The observation instrument was used to collect data about student activity. Documentation is used to collect data related to research files. The interview instrument was used to collect data related to the activeness of students and lecturers. The speaking practice test was used to collect research data on students' speaking ability. The results of this study indicate (1) there was an increase in student activeness in cycle 1 as much as 64.2\% (18 people) and in cycle 2 it increased to 89.2\% (25 people); (2) there was an increase in learning outcomes of speaking skills, namely the pre-cycle that completed by $10 \%$ or 3 people, increased in cycle 1 students who completed 64, 2\% or 18 people while in cycle 2 the level of completeness increased by $89.2 \%$ or 25 person. The conclusion of this research is that the application of the drill-based mind map method can increase the activeness and learning outcomes of students' speaking skills in the PBSI, IKIP PGRI Bojonegoro.
\end{abstract}

Keywords: Talking, Method, Min Map, drill

\section{ABSTRAK}

Penelitian ini dilatarbelakangi rendahnya nilai kemampuan praktik berbicara pada mahasiswa Prodi PBSI IKIP PGRI Bojonegoro. Tujuan penelitian ini untuk mendeskripsikan; (1) peningkatan keaktifan kemampuan berbicara dengan metode mind map berbasis drill pada mahasiswa tingkat IA Prodi PBSI IKIP PGRI Bojonegoro Tahun Akademik 2019/2020; (2) peningkatan hasil belajar kemampuan berbicara dengan metode mind mapberbasis drill pada mahasiswa tingkat IA Prodi PBSI IKIP PGRI Bojonegoro Tahun Akademik 2019/2020. Penelitian ini menggunakan metode Penelitian Tindakan Kelas (PTK) melalui dua siklus, masing-masing siklus terdiri dari perencanaan, pelaksanaan, observasi, refleksi. Pengumpulan data menggunakan instrumen observasi, dokumentasi, wawancara, dan tes praktik berbicara. Instrumen observasi digunakan untuk mengumpulkan data tentang keaktifan mahasiswa. Dokumentasi digunakan untuk mengumpulkan data terkait dengan berkas penelitian. Instrument wawancara digunakan untuk mengumpulkan data terkait dengan respon keaktifan mahasiswa dan dosen. Tes praktik berbicara digunakan untuk mengumpulkan data penelitian tentang kemampuan berbicara mahasiswa. Hasil penelitian ini menunjukkan (1) adanya peningkatan keaktifan mahasiswa pada siklus 1 sebanyak 64,2\% (18 orang) dan pada siklus 2 meningkat menjadi 89,2\% (25 orang); (2) adanya peningkatan hasil belajar keterampilan berbicara yaitu pra-siklus yang tuntas sebesar $10 \%$ atau 3 orang, meningkat pada siklus 1 mahasiswa yang tuntas 64, $2 \%$ atau 18 orang sedangkan pada siklus 2 tingkat ketuntasan meningkat sebesar $89,2 \%$ atau 25 orang. Simpulan penelitian ini adalah penerapan metode mind map berbasis drill dapat meningkatkan keaktifan dan hasil belajar kemampuan berbicara mahasiswa di Prodi PBSI IKIP PGRI Bojonegoro.

Kata Kunci: Berbicara, Metode, Min Map, drill

Submitted Nov 11, 2020| Revised Nov 25, 2020 | Accepted Nov 30, 2020

\section{Pendahuluan}

Berbicara merupakan kemampuan seseorang untuk menyampaikan ide, gagasan, pikiran, dan informasi kepada orang lain dengan tujuan tertentu (Darmuki dkk., 2019; Darmuki dkk., 2018; Darmuki dkk., 2017; Darmukidkk., 2016). Seseorang untuk bisa berbicara dengan baik dan lancar dibutuhkan bahan baku kosa kata dan pemahaman yang diperoleh dari keterampilan membaca dan menyimak (Darmuki dkk., 2018). Dalam konteks ini untuk bisa menjadi pembicara yang baik diawali 
dari pembaca yang baik dan penyimak yang baik. Selain itu keterampilan berbicara harus dilatih berkalikali untuk bisa menghasilkan tampilan yang baik dan lancar (Darmuki\& Hidayati, 2019: 122). Banyak orang pandai menulis tetapi tidak pandai berbicara, ini merupakan fenomena umum dalam keterampilan berbahasa. Maka keterampilan berbicara dianggap keterampilan tersulit dibandingkan dengan keterampilan berbahasa yang lain.

Mata kuliah keterampilan berbicara di Prodi Pendidikan Bahasa dan Sastra Indonesia merupakan mata kuliah yang sangat penting dikuasai oleh mahasiswa untuk melatih kemampuan alur berpikir mahasiswa dalam menyampaikan ide gagasan, pikiran, dan informasi kepada orang lain (Darmuki dkk., 2018: 115 ). Dalam konteks proses belajar mengajar tidak terlepas dari kegiatan berbicara, mulai dari membuka pelajaran sampai menutup pelajaran. Bahkan kemampuan berbicara menunjukkan intelektual/pengetahuan dari orang yang berbicara (Darmuki \& Hariyadi, 2019: 257). Keruntutan dan kelancaran berbicara bisa dilatih berkali-kali sebelum tampil akan membantu kesuksesan dalam berbicara di depan umum. Pentingnya penguasaan keterampilan berbicara tersebut menjadikan perhatian dosen lebih terhadap keterampilan berbicara dibandingkan dengan keterampilan yang lain (Darmuki \& Hidayati, 2019: 122).

Dalam konteks proses pembelajaran partisipasi keaktifan mahasiswa sangat berpengaruh pada proses perkembangan berpikir, emosi, dan sosial. Beberapa upaya yang dapat dilakukan dosen dalam mengembangkan keaktifan belajar mahasiswa dalam mata kuliah keterampilan berbicara dengan meningkatkan minat mahasiswa, membangkitkan motivasi mahasiswa, serta menggunakan media dalam pembelajaran. Keterlibatan mahasiswa dalam belajar, membuat mereka secara aktif terlibat dalam proses pembelajaran sehingga pembelajaran bisa berjalan dengan maksimal.

Permasalahan di Prodi PBSI berdasarkan observasi awal dalam pembelajaran berbicara kenyataannya mahasiswa yang mengambil mata kuliah berbicara kemampuannya masih rendah bahkan jauh dari yang diharapkan. Mahasiswa sebagian besar masih kesulitan untuk berbicara dengan baik dan lancar. Hal ini dipengaruhi oleh banyak faktor mulai dari penggunaan metode pembelajaran dosen yang membosankan, dosen lebih dominan di dalam pembelajaran berbicara, dosen kurang variatif dalam menggunakan metode, penggunaan media pembelajaran juga kurang variatif dll. Mahasiswa sebagian besar juga masih mengalami kesulitan dalam menyampaikan ide, berbicaranya tidak runtut, bahkan ada yang tidak mau berbicara dengan alasan grogi, belum siap, sebagian lagi tidak tahu apa yang akan dia sampaikan ketika berbicara di depan kelas. Selain itu mahasiswa juga merasa perlu waktu untuk berlatih berbicara sebelum tampil di depan kelas agar tidak grogi dll.

Berdasarkan permasalahan di atas dibutuhkan metode khusus yang dapat memberikan kesempatan kepada mahasiswa untuk berlatih berbicara. Kemampuan berbicara seseorang akan baik dan runtut kalau dipersiapkan lebih maksimal melalui latihan terlebih dahulu. Selain itu juga dibutuhkan metode khusus untuk membantu mahasiswa membuat peta konsep untuk berbicara agar kemampuan berbicara mahasiswa baik dan runtut saat tampil di depan kelas.

Salah satu cara agar terampil berbicara dengan baik adalah dengan mempersiapkan alur berpikir dan penguasaan konsep, berlatih berulang-ulang, lalu mempraktikkannya. Dengan menirukan ucapan (bunyi) dan mempraktikkannya, mahasiswa akan belajar mengucapkan kata dengan intonasi, dialek,dan nada suara sesuai dengan alur berpikir dan konsep yang sudah disiapkan.Melalui penggunaan metode mind map berbasis pembelajaran drill diharapkan mampu meningkatkan kemampuan berbicara mahasiswa lebih baik dan lancar karena disiapkan lebih dahulu melalui drill dan peta konsep memberikan gambaran keruntutan berbicara.

Mind map Menurut Liu (2011: 2554) adalah pembelajaran dimana adanya hubungan saling keterkaitan antara konsep dan prinsip yang ditampilkan seperti jejaring konsep yang perlu dikonstruksikan, jejaring konsep yang telah dikonstruksikan inilah yang disebut sebagai mind map.Metode mind map akan membantu mahasiswa untuk berbicara menggunakan alur berpikir logis dan penguasaan konsep (Adeneye,2011; Ajaja, 2011; Akeju, 2012; Alireza dkk., 2012; Bamidele \& Oloyede, 
2013; Barchok dkk., 2013). Pemetaan konsep adalah ide sentral atau konsep yang terpancar keluar dalam ide-ide terkait. Peta konsep juga disebut peta mental, peta pikiran, cluster, pemetaan, kata webbing, alur berpikir atau cabang ide (Lim, Cheng, Lam, \& Ngan 2003: 55; Peterson \& Snyder 1998: 6). Metode pembelajaran drill pada hakikatnya merupakan strategi pembelajaran yang bertujuan untuk memberikan pengalaman belajar yang lebih konkrit melalui latihan langsung yang bertujuan untuk menguji kemampuan kinerja siswa melalui kecepatan menyelesaikan latihan yang diberikan (Erik, 2009: 18).Drill adalah suatu cara mengajar dengan memberikan latihanlatihan terhadap apa yang telah dipelajari siswa sehingga siswa memperoleh suatu keterampilan tertentu (Luik 2007).

Oleh karena itu, metode mind map berbasis pembelajaran drill dipilih karena melalui peta konsep berpikir mahasiswa bisa mengonsep apa yang akan dia bicarakan dan melalui drill diharapkan mahasiswa memiliki kesempatan untuk berlatih sebelum tampil di depan umum. Artinya dengan mind map alur bicara mahasiswa runtut sedangkan melalui drill mahasiswa bisa punya pengalaman berlatih atau mempersiapkan keterampilan berbicara.

\section{MetodePenelitian}

Jenis penelitian yang dilakukan ini jenis penelitian (PTK) dengan pendekatan deskriptif kualitatif. PTK ini terdiri dari 2 siklus, masing-masing siklus terdiri dari perencanaan, pelaksanaan, pengamatan, dan refleksi. Subjek penelitian ini adalah mahasiswa di kelas IA Prodi PBSI IKIP PGRI Bojonegoro Tahun Akademik 2019/2020 semester gasal yang mengambil mata kuliah berbicara dengan jumlah mahasiswa 28 orang yang terdiri dari 8 laki-laki dan 20 perempuan, usia antara 18-25 Tahun. Sumber data dalam penelitian ini berupa proses belajar mengajar mata kuliah keterampilan berbicara dan satu orang pengajar mata kuliah keterampilan berbicara. Data penelitian ini berupa proses pembelajaran mata kuliah Keterampilan Berbicara di kelas IA Prodi PBSI IKIP PGRI Bojonegoro. Pengumpulan data menggunakan observasi, wawancara dan dokumentasi.

Instrumen observasi digunakan untuk mengumpulkan data tentang proses pembelajaran di kelas selama observasi awal, siklus 1 maupun siklus 2. Observasi menggunakan lembar observasi mahasiswa dan lembar observasi dosen dalam proses pembelajaran. Wawancara digunakan untuk mengumpulkan data tanggapan dosen mengenai penggunaan metode pembelajaran awal wawancara, selama siklus 1 maupun siklus 2. Wawancara menggunakan panduan wawancara yang sudah disiapkan secara terstruktur. Teknik pengumpulan data penelitian ini menggunakan dokumentasi, yang digunakan untuk mengumpulkan informasi berupa dokumen terkait dengan penelitian yang dilakukan. Untuk mengetahui hasil belajar berbicara menggunakan instrument tes berupa unjuk kerja yang dilengkapi dengan lembar observasi (Hughes, 2003: 58). Observasi terhadap mahasiswa dilakukan untuk menilai praktik berbicara mahasiswa saat tampil di depan kelas.

\section{HasildanPembahasan}

Berdasarkan observasi peneliti menemukan bahwa keaktifan mahasiswa dalam proses pembelajaran berbicara mahasiswa masih relatif rendah. Rendahnya kemampuan berbicara mahasiswa salah satunya karena dosen belum menggunakan metode pembelajaran yang efektif, kurang menarik dan menyenangkan. Selain itu pembelajaran yang dilakukan dosen masih bersifat konvensional dan membuat pembelajaran membosankan sehingga mahasiswa kurang aktif dalam mengikuti proses pembelajaran di kelas. Metode pembelajaran yang digunakan dosen tidak memberikan motivasi kepada mahasiswa untuk mau belajar berbicara. Mahasiswa tidak tertarik dengan pembelajaran keterampilan berbicara, diperparah dengan persepsi mahasiswa yang menganggap keterampilan berbicara tidak terlalu penting manfaatnya dalam kehidupan sehari-hari.

Berdasarkan hasil observasi tersebut, peneliti bersama dosen melakukan kolaborasi penelitian perbaikan pembelajaran dengan menggunakan metode mind map berbasis drill. Perencanaan perbaikan 
pembelajaran di desain melalui tindakan siklus 1 dan siklus 2 yang masing-masing terdiri dari perencanaan, pelaksanaan, pengamatan (observasi), dan refleksi. Perbaikan pembelajaran pada tindakan siklus 1 dan siklus 2 dengan membagikan angket untuk mengetahui minat mahasiswa dalam pembelajaran setelah menggunakan metode mind map berbasis drill.

Berdasarkan hasil observasi keaktifan mahasiswa dalam pelaksanaan tindakan pada siklus 1 dan siklus 2 dapat dinyatakan bahwa terjadi peningkatan keaktifan pembelajaran berbicara dengan metode mind map berbasis drill. Hal tersebut dapat dilihat bahwa keaktifan mahasiswa dalam mengikuti pembelajaran berbicara meningkat. Peningkatan keaktifan pembelajaran berbicara pada tindakan siklus 1 sebanyak $57 \%$ (16 orang) dan pada tindakan siklus 2 meningkat menjadi 89,2\% (25 orang).Peningkatan keaktifan pembelajaran keterampilan berbicara tersebut dapat dilihat pada tabel di bawah ini.

Tabel 1. Perbandingan Keaktifan Skor Pra-Siklus, Siklus 1, Siklus 2

\begin{tabular}{clccc}
\hline Skor Angket & Kategori & Pra siklus & Siklus 1 & Siklus 2 \\
\hline $\mathbf{8 5 - 1 0 0}$ & Sangat baik & 0 & 0 & 2 \\
$\mathbf{7 0 - 8 4}$ & Baik & 3 & 16 & 23 \\
$\mathbf{5 0 - 6 9}$ & Cukup & 13 & 9 & 3 \\
$\mathbf{3 5 - 4 9}$ & Kurang & 12 & 3 & 0 \\
$\mathbf{> 3 5}$ & Sangat Kurang & 0 & 0 & 0 \\
\hline
\end{tabular}

Berdasarkan tabel di atas bahwa keaktifan mahasiswa terhadap pembelajaran keterampilan berbicara pada pra-siklus kategori kurang baik ada 12 orang $(42,8 \%), 13$ orang $(36,4 \%)$ kategori cukup baik, 3 orang $(10,7 \%)$ kategori baik, dan nol kategori sangat baik. Hasil angket siklus 1 menunjukkan adanya kenaikan dengan rincian 3 orang $(10,7 \%)$ kategori kurang baik, 9 orang (32,1\%) ketegori cukup baik, 16 orang $(57,1 \%)$ kategori baik, dan nol kategori sangat baik. Sedangkan keaktifan mahasiswa terhadap pembelajaran keterampilan berbicara pada siklus 2 kategori kurang baik 0 orang, 3 orang $(10,7 \%)$ kategori cukup baik, 23 orang (82,1\%) kategori baik, dan 2 orang (7,1\%) kategori keaktifannya sangat baik. Keaktifan mahasiswa terhadap pembelajaran keterampilan berbicara dari prasiklus, ke tindakan siklus 1 dan siklus 2 dengan menggunakan metode mind mapberbasis drilterlihat relatif selalu miningkat.

Hal tersebut menunjukkan bahwa penerapan metode mind mapberbasis drilldapat meningkatkan keaktifan belajar keterampilan berbicara mahasiswa. Belajar menggunakan metode mind mapberbasis drill kondisi pembelajaran di kelas lebih aktif/menyenangkan dan tidak membuat bosen. Mahasiswa lebih kreatif dan tidak monoton saat berbicara di depan kelas, isi yang dibicarakan lebih bervariasi.Hal tersebut sesuai dengan teori yang dikemukakan oleh Barchok (2013:539) bahwa keaktifan adalah suatu kecenderungan individu yang menetap, untuk merasa tertarik pada bidang studi atau pokok bahasan tertentu dan merasa senang mempelajari materi itu sehingga muncul tindakan aktif dalam pembelajaran. Lebih lanjut, Bamidele\& Oloyede(2013: 75) bahwa metode pembelajaran mind mapmerupakan pembelajaran yang memiliki dampak pada keaktifan peserta didik membuat peta konsep sehingga pembelajaran lebih menyenangkan, karena dalam membuat peta pikiran, imajinasi dan kreativitas yang tidak terbatas menjadikan pembuatan serta peninjauan ulang peta konsep lebih menyenangkan. Melalui pembelajaran drillmahasiswa merasa punya kesempatan untuk berlatih terlebih dahulu sebelum tampil di kelas (Barry\& King, 2006).

Selain itu, hal yang tidak kalah pentingnya adalah kesadaran para mahasiswa akan tanggung jawabnya yakni belajar. Kesadaran ini harus muncul dalam diri setiap pelajar dan harusdilaksanakan dengan sebaik-baiknya. Belajar bukan karena paksaan dari orang tua maupun kewajiban semata, melainkan belajar sudah dirasakan sebagai tanggungjawab bagi setiap mahasiswa. Hal ini terkait dengan minat internal dari mahasiswa untuk belajar. Sejalan dengan itu, Darmuki dan Hidayati (2019: 17) mengungkapkan bahwa minat belajar yang tinggi cenderung menghasilkan prestasi belajar yang tinggi. Metode mind map dapat meningkatkan minat belajar mahasiswa, hal ini dapat dilihat dari antusiasme 
mahasiswa dalam mengikuti pembelajaran. Mahasiswa juga merasakan penggunaan metode mind map menjadikan pembelajaran tidak membosankan dan lebih menyenangkan.

Metode pembelajaran yang digunakan dosen dalammenyampaikanmateri pada saat proses belajarmengajar berpengaruh kepada hasil belajar mahasiswa. Hal ini terbukti dengan penggunaan metode mind map yang berhasil meningkatkan kemampuan/keterampilanmahasiswa dalam berbicara (Liu, 2011: 2557). Hasil pembelajaran juga membuktikan bahwa dari aspek pengetahuan mahasiswa mengalami peningkatan pada siklus 1 dan siklus 2. Hal ini membuktikan bahwa metode mind map dapat meningkatkan hasil belajar mahasiswa dalam mata kuliah Keterampilan Berbicara. Metode mind map yang digunakan dosen di kelas menjadikan pembelajaran lebih menarik dan tidak membosankan sehingga berdampak pula pada hasil pembelajaran keterampilan berbicara baik dari aspek pengetahuan maupun aspek keterampilan berbicara mahasiswa (Adeneye, 2011: 15). Aspek pengetahuan dan keterampilan mahasiswa meningkat menjadikan mahasiswa alur berbicaranya lebih runtut dan logis sehingga secara kompetensi berbicara mahasiswa lebih kompeten sesuai ketercapaian tujuan pembelajaran.

Tabel 2. Perbandingan Hasil Belajar Pra-Siklus, Siklus 1, dan Siklus 2

\begin{tabular}{clcccc}
\hline Skor Angket & Kategori & Pra Siklus & Siklus 1 & Siklus 2 & Keterangan \\
\hline $\mathbf{8 5 - 1 0 0}$ & Sangat baik & $0(0 \%)$ & $0(0 \%)$ & $4(14,2 \%)$ & Tuntas \\
$\mathbf{7 0 - 8 4}$ & Baik & $3(10,7 \%)$ & $18(64,2 \%)$ & $21(75 \%)$ & Tuntas \\
$\mathbf{5 0 - 6 9}$ & Cukup & $13(46,4)$ & $8(28,5 \%)$ & $3(10,7 \%)$ & Belum Tuntas \\
$\mathbf{3 5 - 4 9}$ & Kurang & $12(42,8)$ & $2(7,14 \%)$ & $0(0 \%)$ & Belum Tuntas \\
$>\mathbf{3 5}$ & Sangat Kurang & $0(0 \%)$ & $0(0 \%)$ & $0(0 \%)$ & Belum Tuntas \\
\hline
\end{tabular}

Berdasarkan data tabel 2 di atas bahwa, hasil belajar mahasiswa dengan penerapan metode pembelajaran mind map berbasis drill menunjukkanadanya peningkatan kemampuan berbicara meningkat. Dalam hal ini KKM yang telah ditetapkan untuk mata kuliah keterampilan berbicara yaitu 70. Darihasil pembelajaran keterampilan berbicara pra-siklus yang tuntas sebesar $10 \%$ atau 3 orang yang tuntas. Pada siklus 1 mahasiswa yang tuntas 64, $2 \%$ atau 18 orang. Pada siklus 2 tingkat ketuntasan meningkat sebesar $89,2 \%$ atau 25 orang. Data tabel tersebut membuktikanbahwa, penerapan metode pembelajaran yang tepat dapat meningkatkan hasil belajar mahasiswa. Hal ini sesuai pendapat Ajaja (2011: 56) bahwa metode mind map dapat meningkatkan hasil belajar secara maksimal. Hasil pembelajaran yang meningkat menunjukkan bahwa kegiatan pembelajaran menggunakan mind map membantu mahasiswa untuk menguasai keterampilan berbicara sekaligus memiliki pengetahuan berbicara. Penguasaan keterampilan dan pengetahuan berbicara menjadikan mahasiswa lebih runtut berbicara dalam menyampaikan ide, gagasan, pikiran dan informasi kepada orang lain di depan kelas. Mahasiswa ketika berbicara di kelas, alur berpikir mahasiswa lebih runtut dan logis, selain itu kreatifitas penyampaiannya tidak monoton. Secara umum pembelajaran menggunakan metode mind map dapat membuat mahasiswa lebih aktif, kreatif, efektif dan hasil belajar menjadi lebih baik serta maksimal (Liu, 2011; Adeneye, 2011; Alireza dkk., 2012).

Berdasarkan hasil siklus 1 dan siklus 2 tersebut, dosen berhasil melaksanakan pembelajaran berbicara dengan metode mind map yang mampu meningkatkan minat dan hasil pembelajaran keterampilan berbicara.Metode mind map juga sebagai sarana bagi dosen untuk membangkitkan minat mahasiswa agar lebih aktif dalam proses pembelajaran berbicara di kelas sehingga pembelajaran lebih menarik dan menyenangkan. Mahasiswa merasa pembelajaran menggunakan mind map lebih menyenangkan dan tidak membosankan, karena mereka bisa belajar dengan kreatif dan tidak monoton. Pembelajaran menggunkan metode mind map secara umum telah berhasil meningkatkan minat dan hasil belajar keterampilan berbicara pada mahasiswa tingkat IA Prodi PBSI IKIP PGRI Bojonegoro Tahun Akademik 2019/2020 Tahun Akademik 2019/2020. 


\section{Kesimpulan}

Berdasarkan hasil penelitian di atas penerapan metode mind map pada mahasiswa kelas IA Prodi PBSI IKIP PGRI Bojonegoro dari siklus 1 dan siklus 2 dapat diperoleh simpulan sebagai berikut: (1) Pembelajaran dengan menggunakan metode mind mapberbasis drilldapat meningkatkan keaktifan belajar mahasiswa sehingga membuat mahasiswa semakin tertarik dan antusias pada mata kuliah keterampilan berbicara yang terlihat dari hasil observasikeaktifan yang meningkat dari pra siklus, siklus 1 ke siklus 2. Hal tersebut dapat dilihat bahwa keaktifan mahasiswa dalam mengikuti pembelajaran berbicara meningkat. Pada siklus 1 sebanyak 64,2\% (18 orang) dan pada siklus 2 meningkat menjadi 89,2\% (25 orang); (2) Pembelajaran dengan mengunakan metode pembelajaran mind mapberbasis drilldapat meningkatkan hasil belajar mahasiswa kelas IA Prodi PBSI IKIP PGRI Bojonegoro dalam mata kuliah Keterampilan Berbicara, peningkatan. Darihasil pembelajaran pra-siklus, siklus 1sampaidengansiklus 2 yaitupra-siklus yang tuntas sebesar $10 \%$ atau 3 orang. Pada siklus 1 mahasiswa yang tuntas 64, $2 \%$ atau 18 orang. Pada siklus 2 tingkat ketuntasan meningkat sebesar 89,2\% atau 25 orang. Secara umum dapat disimpulkan bahwa penerapan metode pembelajaran mind mapberbasis drilldapat meningkatkan keaktifan dan hasil belajarkemampuan berbicara mahasiswa kelas IA Prodi PBSI IKIP PGRI Bojonegoro.

\section{Daftar Pustaka}

Adeneye O. (2011). Effect of Concept Mapping Strategy on Students' Achievement in Junior Secondary School Mathematics. International Journal of Mathematics Trends and Technology, 2(3).1116.

Ajaja O. Patrick. (2011). Concept Mapping As a Study Skill: Effects on Students Achievement in Biology.Int J Edu Sci, 3(1): 49-57.

Akeju O. O. Simpson, Rotimi C. O \& Kenni A. M. (2012). Teaching With Concept Mapping Instructional Strategy in Nigeria Secondary Schools. Eurasian J. Phys. Chem. Educ., Jan (Special Issue):13-19.

Alireza D. M., Ali Mostafaei \& Davood Ghaderi. (2012). Effects of concept mapping instruction on the academic achievement of students in the history course. Annals of Biological Research, 3 (7):3686-3690.

Bamidele, E.F., Oloyede, E. O. (2013). Comparative Effectiveness of Hierarchical, Flowchart and Spider Concept Mapping Strategies on Students' Performance in Chemistry. World Journal of Education. 3(1). 66-76.

Barchok K.H., Too J.K., Ngeno K.J. (2013). Effect of Collaborative Concept Mapping Teaching Strategy on Students' Attitudes Towards Chemistry in Selected Secondary Schools in Kenya. Asian Journal of Social Sciences \& Humanities. 2(2), 530-540.

Barry, K., \& King, L. (2006). Beginning Teaching and Beyond (3 ed.).

Darmuki, A. \& Ahmad Hariyadi. (2019). Eksperimentasi Model Pembelajaran Jucama Ditinjau Dari Gaya Belajar Terhadap Prestasi Belajar Mahasiswa Mata Kuliah Berbicara Di Prodi PBSI IKIP PGRI Bojonegoro. Kredo. 3(1), 62-72.

Darmuki, A. \& Hidayati N.A. (2019). An Investigation of The Cooperative Learning Using Audio Visual Media in Speaking Skill Subject. ICSTI. 121-126.

Darmuki, A. \& Hidayati, N.A. (2019). Peningkatan Kemampuan Berbicara Menggunakan Metode Kooperatif Tipe NHT pada Mahasiswa Tingkat I-A Prodi PBSI IKIP PGRI Bojonegoro Tahun Akademik 2018/2019. Jurnal Pendidikan Edutama. Vol. 6(2), hlm 9-18.

Darmuki, A., Ahmad Hariyadi. (2019). Peningkatan Keterampilan Berbicara Menggunakan Metode Kooperatif Tipe Jigsaw pada Mahasiswa PBSI Tingkat IB IKIP PGRI Bojonegoro Tahun Akademik 2018/2019. Kredo. 2(2), 256-267. 
Darmuki, A., Andayani, Joko Nurkamto, Kundharu Saddhono. (2017). Cooperative, Synectics, and CTL Learning Models Toward Speaking Ability Viewd from Students Motivation. Proceeding International Conference on Intellectuals'Global Responsibility (ASSEHR). Vol. 125, 75-79.

Darmuki, A., Andayani, Joko Nurkamto, Kundharu Saddhono. (2017). Evaluating InformationProcessing-Based Learning Cooperative Model on Speaking Skill Course. Journal of Language Teacbing and Reasearch. 8(1) pp. 44-51.

Darmuki, A., Andayani, Joko Nurkamto, Kundharu Saddhono. (2018). The Development and Evaluation of Speaking Learning Model by Cooperative Approach. International Journal of Instruction. 11(2), 115-128.

Darmuki, A., Ahmad Hariyadi, Nur Alfin Hidayati. (2019).Developing Beach Ball Group Investigations Cooperative. International ConferencesSeword Fresh, 1-7.

Darmuki, Agus. (2013). Pembelajaran Menulis Puisi dalam Pembentukan karakter Berdasarkan Kurikulum 2013.Seminar Nasional Inovasi PBSI dalam Kurikulum 2013. Vol. 1, 34-40.

Erik, M. A. (2009). Efektivitas Peningkatan Hasil Belajar Dengan Menggunakan Multimedia Interaktif Model Drill And Practice Dalam Pembelajaran TIK. Skripsi Jurusan Pendidikan Ilmu Komputer UPI: Tidak diterbitkan.

Hughes, Arthur. (2003). Testing for Language Teacher. Second Edition. Cambridge University Press.

Liu, P. (2011). A Study on the Use of Computerized Concept Mapping to Assist ESL Learners' Writing. Computers \& Education, vol.57(4), pp. 2548-2558.

Lim, S.E., Cheng, P.W.C., Lam, M.S. \& Ngan, S.F. (2003). Developing Reflective and Thinking Skills by Means of Semantic Mapping strategies in Kindergarten Teacher Education. Early Child Development and Care. 172(1):55-72.

Luik, P. (2007). Characteristics of drills related to development of skills. Journal of Computer Assisted Learning 23, 56-68.

Peterson, A.R. \& Snyder, P.J. (1998). Using Concept Maps to Teach Social Problems Analysis. Paper presented at the Annual Meeting of the Society for the Study of Social Problems. Columbus State Community College. San Francisco. 5-28. 